Dokuz Eylül Üniversitesi-Mühendislik Fakültesi

Fen ve Mühendislik Dergisi

Cilt 20, Sayı 60, Eylül, 2018
Dokuz Eylul University-Faculty of Engineering Journal of Science and Engineering Volume 20, Issue 60, September, 2018

DOI: $10.21205 /$ deufmd. 2018206056

\title{
CdSe Nanokristalleri ile Mikrokapsül Hazırlama ve Cr(VI) Gideriminde Kullanılması
}

\author{
Ayşe ALTUNYALDIZ1 ${ }^{\text {, Canan BAŞLAK }}{ }^{* 2}$, Gülşin ARSLAN ${ }^{3}$ \\ 1,2,3Selçuk Üniversitesi, Fen Fakültesi, Kimya Bölümü, 42075, Konya \\ 1ORCID: 0000-0002-5149-0658 \\ 2 ORCID: 0000-0003-1444-1272 \\ 3 ORCID:0000-0002-4836-8651
}

(Alınış / Received: 08.05.2017, Kabul / Accepted: 21.02.2018 Online Yayınlanma / Published Online: 15.09.2018

Anahtar Kelimeler Özet: Bu çalışmada, yüksek sıcaklıkta organometalik başlatıcılar ile CdSe nanokristal 1 , Cr(VI) sorpsiyon

2,

Kuantum noktacık yapı 3, Mikrokapsül 4, ağır metal temelli CdSe nanokristalleri sentezlenmiş ve kitosan katkılı mikrokapsüllerin hazırlanması ile yeni bir nanokompozit mikrokapsül adsorban maddenin sulardan $\operatorname{Cr}(\mathrm{VI})$ gideriminde kullanılması amaçlanmıştır. Sentezlenen CdSe nanokristallerinin geçirimli elektron mikroskobu tekniği (TEM) ve X ışınları saçılım (XRD) ölçümleri ile yapısal analizleri yapılmıştır. Mikrokapsüllere ait adsorpsiyon kapasiteleri, başlangıç metal iyonu konsantrasyonları, $\mathrm{pH}$, zaman ve adsorban dozunun adsorpsiyona etkileri Batch metoduna göre Cr(VI) iyonunun sulu çözeltilerden uzaklaştırılması araştırılmıştır. Cr(VI) metal-sorpsiyon işlemlerinde denge sorpsiyon izoterm eğrileri Freundlich ve Langmuir sorpsiyon izotermleri kullanılarak çizilmiş ve bu izotermlerden adsorpsiyon parametreleri hesaplanmıștır.

Preparation of Microcapsules with CdSe Nanocrystals and The Use of Microcapsules for Cr (VI) Removal From Water

Abstract: In this work, CdSe nanocrystals based on heavy metals CdSe nanocrystal 1 , are synthesized with organometallic precursors at high temperature and it is aimed to use a new nanocomposite microcapsule adsorbent material for $\mathrm{Cr}$ (VI) removal from water by preparation of chitosan-doped microcapsules. Structural analyzes of synthesized CdSe nanocrystals were performed by transmission electron microscopy (TEM) and X-ray diffraction (XRD) measurements. The adsorption capacities of the microcapsules, initial metal ion concentrations, $\mathrm{pH}$, time and adsorption effects of adsorbent dose were investigated in order to remove $\mathrm{Cr}$ (VI) ion from aqueous solutions according to the Batch method. In Cr (VI) metal-sorption processes, equilibrium sorption isotherm curves were drawn by using Freundlich and Langmuir sorption isotherms and the adsorption parameters were calculated from these isotherms. 

punto olacak șekilde buraya eklenmelidir

\section{Giriş}

21. yüzyllın en önemli öncelikli konularından birisi temiz su ihtiyacının sağlanması olup su temininde ileri teknolojilerin kullanılması ve geliștirilmesi önem arz etmektedir. Elektro kaplama endüstrisinde, patlayıcı madde yapımında, boya kağıt üretiminde, deri tabaklama prosesinde ve metalurji sanayiinde korozyon kontrol ajanı olarak çok sıklıkla krom kullanılmaktadır. Bu tür işletmelerin atıklarında toksik yapıda olan $\mathrm{Cr}(\mathrm{VI})$ sulara karışmaktadır [1]. Krom ve türevlerinin su kalitesini olumsuz etkilemeyecek aralıklarda tutulması için suların arıtılması gerekir. Su arıtımında koagülasyon-flokülasyonçöktürme, adsorpsiyon, iyon değişim ve membran yöntemleri veya bu yöntemlerin kombinasyonu kullanılmış olup en etkin yöntemlerden birisi adsorpsiyon yöntemi olarak belirtilmektedir [2]. Adsorpsiyon, atık arıtımında maliyet düşüklüğü ve çevre dostu olması nedeni ile tercih edilen ileri bir arıtım yöntemidir. Adsorpsiyonun önemli avantajlarından biri, geleneksel atık su arıtma tesislerinden çıkan fazla çamur oluşumunun bu işlemde görülmemesidir [3, 4]. Adsorban madde olarak aktif karbon, çeșitli polimerler, reçineler, uçucu kül, jeller, alüminyum oksit, silikatlar, saman, talaş, killer, çeşitli bitki türleri, zeolitler gibi birçok madde kullanılmıştır. Adsorpsiyon işlemini daha etkin ve az maliyetli bir hale getirmek için, ucuz ve yenilenebilir adsorbanlar bulmaya çalışılması gerekmektedir [2, 57].

Çağımızın en önemli gelişen bilimi olan nanoteknolojide önemli bir yere sahip olan mikrokapsüller pek çok alanda gelişme kaydederek modern çağın aranılan çözüm yöntemi haline gelmiştir [8, 9]. Mikrokapsüllerden, çözelti veya süspansiyon halindeki enzim veya proteinlerden başka, hücre özütleri, bakteriler, radyoaktif işaretli veya manyetik özellikte maddeler, kofaktörleri içeren karmaşık enzim sistemleri, kontrollü ilaç salınım sistemleri, adsorban granülleri de tutuklama konusunda kullanılmışlardır [10]. Kapsüllemede kullanılan zarlar, sentetik veya biyolojik olabilir [11]. Sentetik zarlar; selüloz nitrat, selüloz asetat, naylon, poliüretan olabilir. Biyolojik zarlar canlı sistemde parçalanabilen protein, lipoprotein, lipit, poliakrilik asit, alginik asit gibi maddelerden oluşabilir. Kapsülleme ajanı olarak bazı karbonhidratlar (nişasta, maltşekeri, dekstroz vb), gumlar (arabik gum, akakia gum, alginate, karrageenans vb), proteinler (süt, jelatin vb) [12] ve kitosan $[13,14]$ en sık kullanılandır. Kitosanın biyouyumlu ve biyobozunur olması, toksik olmamasının yanısıra mükemmel adsorpsiyon özelliği yaşamın birçok alanında kitosanı aranan bir biyopolimer haline getirmiştir [15]. Kitosan, su arıtma işlemlerinde kullanılmaktadır [16]. Su arıtım tesislerinde kitosan; yağ [17] ve ağır metallerin [18] giderilmesinde ayrıca flokülasyon ve koagülasyon ajanı [19], olarak da kullanılmaktadır.

\begin{tabular}{lcr}
\multicolumn{2}{c}{ Teknolojik çalışmalarda özellikle } \\
farklı yapıda & nanomalzemelerin \\
geliştirilmesine & odaklanılmış ve \\
nanomalzemelerin & mikrokapsül
\end{tabular} üretiminde kullanılması ve böylece su arıtımı alanında etkin, verimli ve sürdürülebilir bir sonuç olarak önerilmektedir [10]. Özellikleri bakımından son yıllarda oldukça çok dikkat çeken kuantum nanokristaller çok geniș ve farklı alanlarda araștırma konusu olarak kullanılmakta olan nano yapılı malzemelerdir. Çok küçük parçacık boyutuna sahip olmaları ve floresans spektrumlarının simetrik ve dar olması ayrıca kararlılıklarının da oldukça yüksek olması bu malzemelerin çok çeşitli çalışma alanlarında tercih edilmesinin 

punto olacak șekilde buraya eklenmelidir

sebebidir $\quad[20, \quad 21]$ Kuantum nanokristallerin sentezi en temel şekilde $\mathrm{Ag}, \mathrm{Hg}, \mathrm{Pb}, \mathrm{Zn}, \mathrm{Cd}$, In gibi bir metal iyonunun ligandın ilavesinden sonra S, Se, Te, veya $P$ gibi kalkojenitlerle çöktürülmesi ile gerçekleştirilir. Misel metodu, solvatermol metot [22] gibi pek çok elde edilme yöntemi olması ile birlikte, bu yöntemler içinde çok popüler olan organometalik sentez rotası CdSe gibi nanokristallerin sentezinde yaygın bir șekilde kullanılmaktadır. Bu sentez yöntemlerinde genellikle trioktilfosfin oksit (TOPO) sabitleyici olarak kullanılırken reaksiyon ortam sıcaklığı olarak $300{ }^{\circ} \mathrm{C}$ gibi yüksek sıcaklıklar tercih edilmektedir. Reaksiyonun kontrollü götürülmesi halinde, özellikle organik çözeltiler içinde gerçekleştirilen bu sentez yöntemlerinde elde edilen kristallerin boyutları 2-8 $\mathrm{nm}$ aralığında ve oldukça homojen bir dağılıma sahiptir [23].

Kuantum nanokristaller, iletken olmaları yanında, parçacık büyüklüğüne bağlı olarak olağanüstü lüminesans özelliklerine ve yüksek kuantum verimine de sahiptirler [24]. $\mathrm{Bu}$ özellikleri sayesinde hücre görüntüleme [25], biyokimyasal tayinler [26], floresans sensör probları [27] ve elektronik cihaz yapımından [28] kimyasal analizlere [29] kadar pek çok alanda bu malzemeleri kullanmak mümkündür [30] Son yıllarda kullanıldıkları bir uygulama alanı da mikrokapsül yapımıdır.

Nanopartiküllerle fonsiyonlandırılmış mikrokapsüller biyoloji, enzimatik katalizleme ve farmakoloji gibi pek çok bilimsel alanda yaygın bir materyal olarak kullanılmaktadır. Molekül veya nanopartikül gibi fonsiyonlaştırıcl malzeme kapsülün içinde tutunarak fonksiyonlama gerçekleştiriliyor. Genel olarak fonksiyonlama; kapsüllerin görüntülenmesi ve belirlenmesine yarayan yariiletken nanokristallerle, mağnetik bir alanda hibrit kapsüllerin yönlendirilmesi amacıyla kullanılan mağnetik nanopartiküller ile veya özel reaksiyonların oluşması ve yeniden düzenlenmesine müsaade eden aktif bileşenler kullanılarak gerçekleştirilir. Multi fonksiyonlandırılmış mikrokapsüllerin avantajları fonksiyonlama özelliklerinin aynı anda tek bir kapsül içine yüklenebilmesidir [31].

$\mathrm{Bu}$ amaçla, sulardan $\mathrm{Cr}(\mathrm{VI})$ iyonlarının uzaklaştırılması için yüksek sıcaklıkta organometalik başlatıcılar ile ağır metal temelli CdSe nanokristalleri sentezlenmiş ve kitosan katkılı yeni bir nanokompozit mikrokapsüller hazırlanarak adsorpsiyon prosesindeki performansı incelenmiştir.

\section{Materyal ve Metot}

\subsection{CdSe nanokristal sentezi}

Kadmiyum oksit (CdO, \% 99,99), Oleik asit $\left(\mathrm{OA}, \mathrm{C}_{14} \mathrm{H}_{28} \mathrm{O}_{2}, \% 90\right)$, Trioktilfosfin oksit (TOPO, $\mathrm{C}_{24} \mathrm{H}_{51} \mathrm{OP}, \% 97$ ), Oleilamin (OLA, $\left.\mathrm{C}_{18} \mathrm{H}_{37} \mathrm{~N}, \% 70\right)$, 1-Oktadesen (ODE, $\left.\mathrm{C}_{18} \mathrm{H}_{36}, \% 95\right)$, Trioktilfosfin (TOP, $\mathrm{C}_{24} \mathrm{H}_{51} \mathrm{P}$, \%97), Kloroform ( $\left.\mathrm{C}_{6} \mathrm{H}_{5} \mathrm{Cl}, \% 99\right)$, Tolüen $\left(\mathrm{C}_{6} \mathrm{H}_{5}-\mathrm{CH}_{3}, \quad \% 99,9\right)$, Selenyum (Se, \%99,99), Etanol $\left(\mathrm{C}_{2} \mathrm{H}_{5} \mathrm{OH}, \% 99,5\right)$, Aseton $\left(\mathrm{C}_{3} \mathrm{H}_{6} \mathrm{O}, \% 99,5\right)$, Hekzan $\left(\mathrm{C}_{6} \mathrm{H}_{14}, \% 95\right)$, Metanol ( $\left.\mathrm{CH}_{3} \mathrm{OH}, \% 99,8\right), 2$ 2-propanol $\left(\mathrm{C}_{3} \mathrm{H}_{7} \mathrm{OH}, \quad\right.$ \%99,5) Sigma-Aldrich firmasından temin edilmiștir.

CdSe nanokristaller organometalik sentez yöntemi ile hazırlanmıştır. İki boyunlu balon içerisine $\mathrm{CdO}(0,05 \mathrm{~mol}), \quad \mathrm{OA}$ $(0,2 \mathrm{mmol})$, TOPO $(0,5 \mathrm{~g})$, OLA $(1 \mathrm{~mL})$ ve ODE (3mL) konuldu ve bu karışım geri soğutucu altında 1,5 saat $150^{\circ} \mathrm{C}^{\prime} \mathrm{de}$ karıștırılarak azot gazına doyuruldu. Bașka bir düzenekte iki boyunlu balon içerisine Se $(0,5 \mathrm{mmol})$, TOP (1 $\mathrm{mL})$ ve OLA (3mL) eklenerek geri soğutucu altında 1,5 saat $70^{\circ} \mathrm{C}^{\prime}$ de karıştırılarak azot gazına doyuruldu. Se'lu karıșım CdO'li karıșıma sıcaklık $150^{\circ} \mathrm{C}$ sabit iken enjekte edilerek reaksiyon bașlatıldı ve daha sonra karıșım $285^{\circ}$ C'ye kadar ısıtıldı. 30 sn sonra reaksiyon sonlandirldı. Elde edilen CdSe nanokristallerine 4 farklı çözücü kullanılarak yıkama işlemi yapıldı. 

punto olacak șekilde buraya eklenmelidir

Bunlar; etanol(1/1), aseton (1/1), hekzan/metanol(1/2), 2 propanol/metanol(1/2) oranlarinda her biri için $3 \mathrm{kez} 5 \mathrm{dk} 5000$ rpm'de santifüj yapıldı. Yıkama işleminden sonra kırmızıkoyu kahve görünümlü toz haldeki nanokistaller kurumaya bırakılmıştır. İnert gaz ortamında ve yüksek sıcaklıkta karıșmakta olan metal ligand karıșımına başlatıcı reaktif enjekte edilerek, sentezlerde ağır metaller katyonik başlatıcı, Se, Te ve $\mathrm{S}$ gibi kalkojen elementler ise anyonik başlatıcı olarak kullanılmaktadır. Anyonik başlatıcının çözeltileri, kalkojen element tozunun yüksek sıcaklıkta kullanılabilen yüzey aktif maddeler içerisinde çözdürülmesi ve bu esnada ortamdan azot gazı geçirilmesi ile hazırlanır. Kalkojen maddenin tamamen çözünmesi neticesinde bu çözelti sıcak olarak, azot gazı ortamında karışmakta olan sıcak metal-ligand karıșıma eklenerek reaksiyon başlatılır [32].

\subsection{Kitosan ile mikrokapsül hazırlama} Kitosan (Orta moleküler ağırlıkta) SigmaAldrich, Asetik asit (\%60), Glutaraldehit (\%25), Metanol ve $\mathrm{NaOH}$ Merck firmasından temin edilmiştir. Kitosan (3 g) \%2'lik Asetik asit çözeltisine $(150 \mathrm{~mL})$ ilave edilerek 24 saat karıștırılarak çözülür. Kitosan çözeltisine CdSe nanokristalinin $1 \mathrm{~mL}$ toluen içindeki çözeltisi ilave edilerek homojen bir karışım hazırlanmıştır. $\mathrm{Bu}$ karışım, koagülasyon çözeltisine (1 litre için; 600 $\mathrm{mL}$ metanol, $400 \mathrm{~mL}$ su ve $120 \mathrm{~g} \mathrm{NaOH}$ ) damlatılarak mikrokapsüller hazırlanmıștır ve 24 saat bekletildikten sonra; süzülerek $\mathrm{pH}$ 'sı nötral oluncaya kadar yıkanmıştır. Mikrokapsüllere çapraz bağlamanın gerçekleşmesi için 90 $\mathrm{mL}$ metanol ve $0,9 \mathrm{~mL}$ gluteraldehit ilave edilerek, 6 saat boyunca $70^{\circ} \mathrm{C}$ 'da geri soğutucu altında karıştırılmıştır. Soğutulan mikrokapsüller saat camı üzerinde oda sıcaklığında kurumaya bırakılmıştır [33].

\subsection{Kesikli (Batch) adsorpsiyon} çalışmaları

$\mathrm{Cr}(\mathrm{VI})$ stok çözeltisi $\mathrm{K}_{2} \mathrm{Cr}_{2} \mathrm{O}_{7}$ 'In deiyonize suda çözünmesiyle hazırlanmıştır. Deneyler için istenen konsantrasyondaki çözeltiler, stok çözeltinin deiyonize su ile seyreltilmesiyle elde edilmiştir. Çözelti $\mathrm{pH}^{\prime \prime} 10,1 \mathrm{~mol} / \mathrm{L} \mathrm{HCl}$ ve $0,1 \mathrm{~mol} / \mathrm{L} \mathrm{NaOH}$ çözeltileri yardımıyla istenen aralıklarda Thermo Orion 420A+ pH metre ile ayarlanmıştır. Mikrokapsüllere ait adsorpsiyon kapasiteleri, başlangıç metal iyonu konsantrasyonları, pH, zaman ve adsorban dozunun adsorpsiyona etkileri Batch metoduna göre $\mathrm{Cr}(\mathrm{VI})$ iyonunun sulu çözeltilerden uzaklaştırılması çalıșmasında araștırılmıștır. Adsorpsiyon işlemleri sonrası mavi bant süzgeç kağıdından süzülen çözeltideki krom miktarları Atomik Absorpsiyon Spektrofotometre (Contr AA 300, Analytik Jena) ile tayin edilmiştir.

\section{Bulgular \\ 3.1 Yapısal Özellikler}

Elde edilen nanokristallerin optik ve yapısal karakterizasyonları yapılmıştır. CdSe nanokristalleri ile hazırlanmış çözeltilerin gün ışığı ve UV lamba altındaki görüntüleri Şekil 1'de görülmektedir. Nanokristallerin çözeltileri gün ışığı altında renkli görünürken, UV lamba ile uyarıldığında turuncu renkte emisyon verdikleri ve reaksiyon süresinin uzaması ile emisyon şiddetinde de artış olduğu gözlenmiştir.

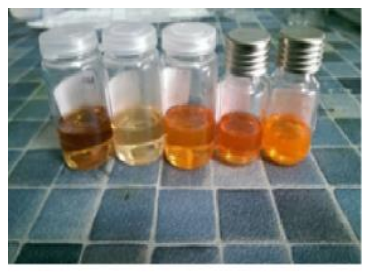

a 
A. Soyadı vd. / Çalışmanın ismi her kelimenin ilk harfi büyük (bağlaçlar hariç) ve "Cambria” fontunda 8 punto olacak șekilde buraya eklenmelidir

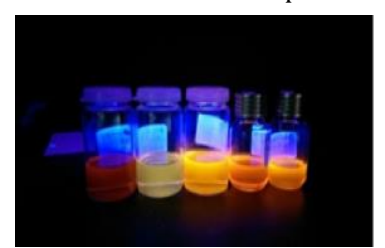

b

Şekil 1. CdSe nanokristal çözeltileri; a) Gün ışığında, b) UV lamba altındaki görüntüleri (soldan sağa doğru 5, 10, 20, 30, 40 sn'lerde reaksiyon ortamından alınan nanokristal çözeltileri).

Elde edilen nanokristallerin geçirimli elektron mikroskobu (TEM) görüntüleri Şekil 2'deki verilmiștir. Şekil 2a ve b'de 2propanol/metanol ile yıkanan nanokristaller, Şekil 2c ve d'de ise hekzan/metanol karışımı ile yıkanan nanokristallerin TEM görüntüleri vardır. Şekillerden anlaşıldığı gibi parmak izi şeklinde görülen nanokristallerin boyutları yaklaşık 3 nm'dir. Elde edilen TEM sonuçlarına dayanarak kristallerin parçacık boyutu dağılımının oldukça dar bir aralıkta ve homojen olduğunu söylemek mümkündür.

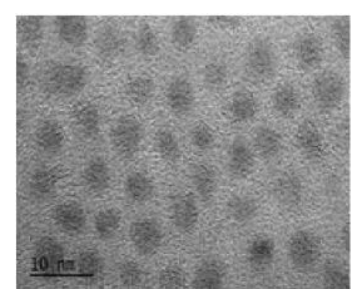

a

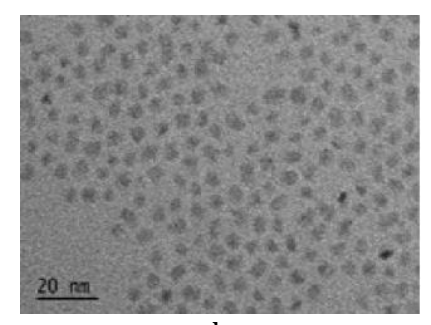

b

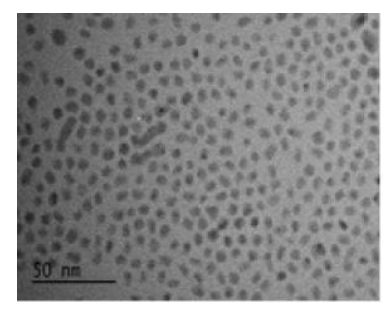

C

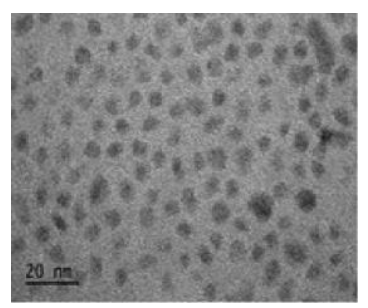

d

Şekil 2. a) ve b) 2-propanol/metanol karışımı ile yıkanan, c) ve d) hekzan/metanol karışımı ile ylkanan CdSe nanokristallerinin TEM görüntüleri.

Nanokristal sentezi sırasında kristallerin büyümesini kontrol etmek amaciyla belirli zaman aralıklarında ortamdan numune çekilerek reaksiyon sonlandırılmıștır. Örneklerin absorpsiyon ve floresans spektrumları alınmıştır. Elde edilen nanokristallerin floresans ve absorbans spektrumları Şekil 3'de görülmektedir. Reaksiyon süresi arttıkça emisyon pik şiddetleri artış göstermiş, pik genişlikleri daha da daralmış ve pikler kırmızı bölgeye doğru kaymıştır.

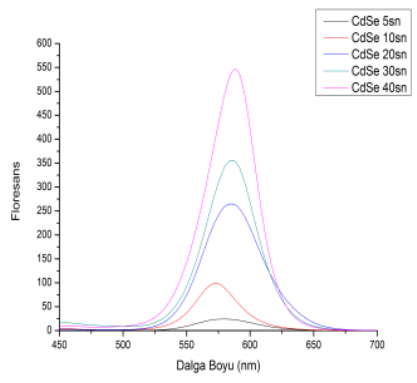


A. Soyadı vd. / Çalışmanın ismi her kelimenin ilk harfi büyük (bağlaçlar hariç) ve "Cambria” fontunda 8 punto olacak șekilde buraya eklenmelidir

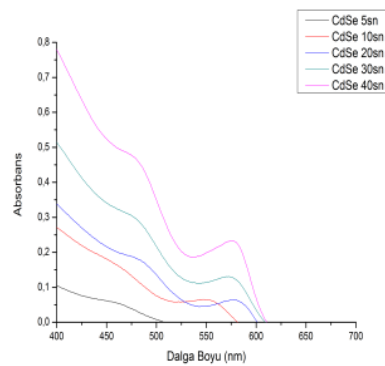

b

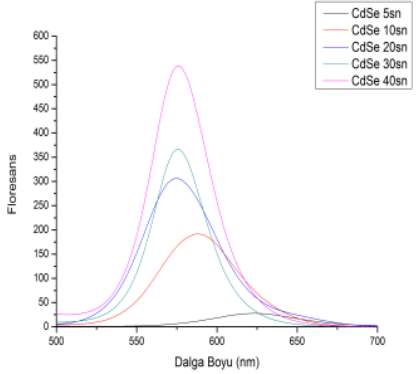

C

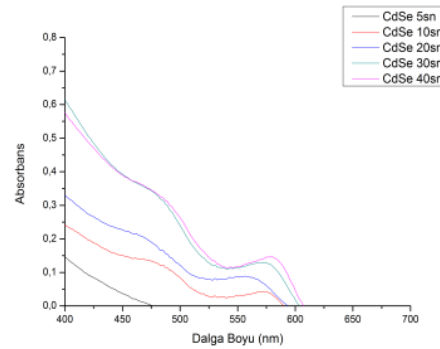

d

Sekil 3. CdSe nanokristallerinin; 2propanol/metanol çözücüsüyle yıkanan; a) Floresans ve b) Absorbans spektrumları. Hekzan/metanol çözücüsüyle yıkanan; c) Floresans ve d) Absorbans spektrumları.

Şekil 3'deki durum kristal yapıların zamanla büyüdügünün göstergesidir. Aynı şekilde absorsiyon pikleri de kırmızı bölgeye doğru kayma göstermiş ve pikler reaksiyon süresi uzadıkça daha da belirgin tepe noktası vermiștir. Bu durum, 10 sn'lik bir senteze göre 40 sn'de gerçekleştirilen bir sentezde oluşan kristallerin yüzeylerinin daha düzgün ve yüzey hatasının daha az olduğunu göstermektedir. CdSe nanokristalleri sentezlendikten sonra ortamdaki fazla olan reaktiflerin giderilmesi için yıkama işlemi yapılmıştır. Bunun için 2 farklı çözücü karışımı (propanol/metanol ve hekzan/metanol) kullanılmıştır. 2propanol/metanol çözücüsüyle yıkanan CdSe nanokristallerinin floresans spektrumuna göre emisyon piklerinde çok küçük bir miktarda sağa kayma gözlenmiş bu parçacık boyutunun bir miktar daha arttığını göstermiștir. CdSe nanokristalleri hekzan/metanol karışımı ile yıkandığında ise emisyon pikleri 5 sn'den 20 sn'lik senteze kadar sola kaymış ve sonrasında piklerin tepe noktasında değişme olmamıştır. Sonuç olarak bu durum farklı çözücüler kullanıldığında parçacık boyutunun değişebileceğini göstermektedir.

CdSe nanokristallerinin yapısal analizi için X ışınları saçılım spektrumları Şekil 4'te alınmıştır. 2-propanol/metanolle ylkanan CdSe nanokristalleri, hekzan/metanolle yıkananlara göre daha az saçlma göstermektedir. Oluşan parçacıkların boyutları yaklaşık $3 \mathrm{~nm}$ civarındadır. Kristal yapıları literatürle uyumludur [34, 35]

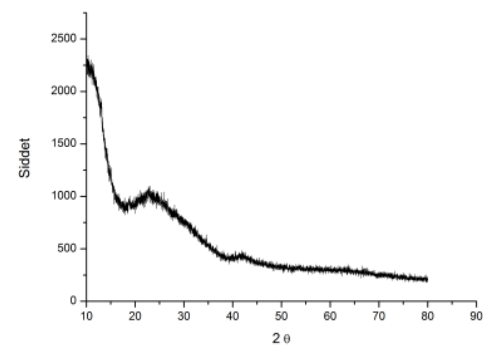

a

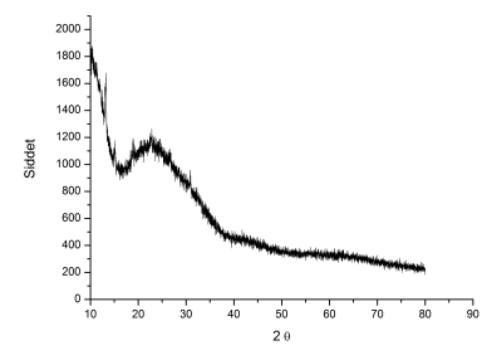

b

Şekil 4. CdSe nanokristallerinin XRD spektrumu; a) 2-propanol/metanol çözücüsüyle yıkanan; b) Hekzan/metanol çözücüsüyle yıkanan. 


\subsection{Mikrokapsüllerle Cr(VI) Giderimi 3.2.1 Adsorban Miktarının Etkisi} 0,$0500 ; 0,0750 ; 0,1000 ; 0,1500$ ve 0,2000 g olarak tartılan mikrokapsüller ayrı ayrı șișelenip $10 \mathrm{mg} \mathrm{L}^{-1} 25 \mathrm{~mL} \mathrm{Cr}(\mathrm{VI})$ metal çözeltisinden şişelere ilave edilerek 25 ${ }^{\circ}{ }^{\prime}$ 'de inkübatörde $200 \mathrm{rpm}$ de 6 saat çalkalanmıștır. Çalkalama sonrasında mavi bant süzgeç kağıdı ile süzülmüştür. Süzüntülerin metal analizleri Contra AA 300'de yapılmıștır. Mikrokapsüller tarafından tutulan metal miktarı ile çözelti fazında kalan metal miktarının toplamının başlangıçta mikrokapsüllerle ilave edilen metal konsantrasyona eşit olup olmadığı kontrol edilmiştir.

Şekil 5'te görüldügü gibi adsorban miktarı artarken sorpsiyon artmakta, bir plato değerine ulașmaktadır. $\mathrm{Bu}$ değerden sonra adsorban miktarının artması sorpsiyonu etkilememektedir. $\mathrm{Cr}(\mathrm{VI})$ iyonlarının adsorbanlar tarafindan \% sorpsiyonu belli bir adsorban miktarına (yaklaşık 0,1000 g) kadar artmıștır. 0,10 gram adsorban miktarı $10 \mathrm{mg} \mathrm{L}^{-1} \mathrm{Cr}(\mathrm{VI})$ çözeltisi için maksimum sorpsiyonu sağlamıștır. $\mathrm{Cr}(\mathrm{VI})$ iyonunun adsorban miktarının arttırılması ile sırasıyla $2>1>$ 0 şeklinde sorpsiyon görülmüștür. $\mathrm{Cr}(\mathrm{VI})$ iyonunun adsorpsiyon kapasitesi 0 -Boş kapsül için 11,22; 1-Hekzan/metanol çözücüsüyle yıkanan için 15,$35 ; 2-2$ propanol/metanol çözücüsüyle ylkanan için ise 26.,82 $\mathrm{mg} / \mathrm{g}$ olarak hesaplanmıştır.

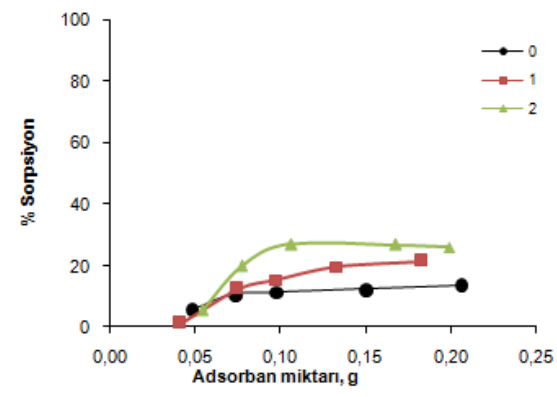

Şekil 5. Mikrokapsüllerin $\mathrm{Cr}(\mathrm{VI})$ giderimi üzerine adsorban miktarının etkisi ( $\mathrm{Cr}(\mathrm{VI})$ konsantrasyonu: $10 \mathrm{mg} \mathrm{L}^{-1}, \mathrm{pH}$ : 5,41, sicaklık: $25^{\circ} \mathrm{C}$, karıștırma oranı: $200 \mathrm{rpm}$, temas süresi: 6 saat)

0-Boş kapsül; 1- Hekzan/metanol çözücüsüyle yıkanan; 2- 2-propanol/metanol çözücüsüyle ylkanan

\subsubsection{Temas Süresi}

$0,1000 \mathrm{~g}$ olarak tartılan mikrokapsüller ayrı ayrı şişelenip $10 \mathrm{mg} \mathrm{L}^{-1} 25 \mathrm{~mL} \mathrm{Cr}(\mathrm{VI})$ metal çözeltisinden şişelere ilave edilerek $25{ }^{\circ} \mathrm{C}$ 'de inkübatörde $200 \mathrm{rpm}$ de 2, 4, 6 ve 12 saat çalkalanmıștır. Çalkalama sonrasında mavi bant süzgeç kağıdı ile süzülmüştür. Süzüntülerin metal analizleri Contra AA 300'de yapılmıştır. Şekil 6'da grafik incelendiğinde, 6 saate kadar olan temas sürelerinde adsorplanan metal miktarı giderek artmakta, ancak 6 saat sonrasındaki ölçümlerde temas süresinin etkin olmadığı görülmektedir. Başlangıçta hızla artan adsorpsiyon gözlenmesi, adsorbanların geniş yüzey alanına sahip ve adsorpsiyon merkezlerinin serbest olması nedeniyle $\mathrm{Cr}(\mathrm{VI})$ iyonlarının kolayca etkileșebilmesinden kaynaklanmaktadır. Yüzeydeki adsorpsiyon merkezleri $\mathrm{Cr}(\mathrm{VI})$ iyonlarıyla tutuldukça, adsorbanın dış yüzeyinden iç yüzeyine doğru taşınmasıyla tutunma meydana gelir ve belli bir süre sonra dengeye gelecektir [6].

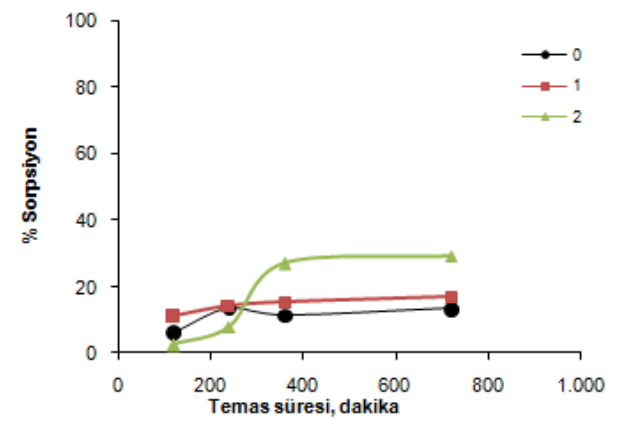

Şekil 6. Mikrokapsüllerin $\mathrm{Cr}(\mathrm{VI})$ giderimi üzerine temas süresinin etkisi (Cr(VI) konsantrasyonu: $10 \mathrm{mg} \mathrm{L}^{-1}$, adsorban miktarı: 0,1000 g, pH: 5,41, sıcaklık: $25^{\circ} \mathrm{C}$, karıștırma oranı: $200 \mathrm{rpm}$ )

0-Boş kapsül; 1- Hekzan/metanol çözücüsüyle yıkanan; 2- 2-propanol/metanol çözücüsüyle ylkanan 


\subsection{3 pH Etkisi}

Ortamın pH'ına bağlı olarak adsorban yüzeyindeki aktif bölgeler için $\mathrm{Cr}(\mathrm{VI})$ iyonlarının hidrojen iyonları arasında bir yarışma söz konusu olup metalin çökmesi veya hidrolizi sonucu çözünen türlerin konsantrasyonu değişeceğinden adsorpsiyon derecesi de değișecektir. Ayrıca adsorbanın yüzey yükünü, iyonlaşma derecesini ve adsorplanan türlerde değișecektir. $\mathrm{Bu}$ temel nedenlerden dolayı farklı $\mathrm{pH}$ değerlerinde $\mathrm{Cr}(\mathrm{VI})$ gideriminin $\mathrm{pH}$ etkisini incelemek amacıyla Cr(VI) metal çözeltisinin farklı pH'larda çözeltisi $0.1 \mathrm{M} \mathrm{NaOH}$ ve $0.1 \mathrm{M}$ $\mathrm{HCl}$ kullanılarak değiştirilmiştir (pH: 1,75, $2,60,3,60,4,38,5,41,6,60)$. Sonuçlar $\mathrm{pH}$ değişimine karşı \% sorpsiyon değerleriyle grafiklendirilmiştir (Şekil 7).

Kitosan mikrokapsüllerin metal tutma miktarı ortamın pH'sından çok etkilenmektedir. Kuvvetli asidik ortamda, adsorplanan metal katyonlarının kitosandan desorplandığı ve bazik ortamlarda ise metal katyonlarının hidroksitleri halinde çöktüğü görülmüștür (Sargın ve ark., 2015). Şekil 7'den görüldüğü gibi, pH 1,75'de Cr(VI) iyonunun adsorpsiyon kapasitesi 0 -Boş kapsül için 54,73; 1-Hekzan/metanol çözücüsüyle yıkanan için 62.,22; 2-2propanol/metanol çözücüsüyle yıkanan için ise $71,57 \mathrm{mg} / \mathrm{g}$ olarak $\mathrm{Cr}(\mathrm{VI})$ giderilirken bu oran $\mathrm{pH} 6.60$ 'da 0 -Boş kapsül için 11,22; 1-Hekzan/metanol çözücüsüyle yıkanan için 15,35; 2-2propanol/metanol çözücüsüyle yıkanan için ise 26,82 mg / g olarak Cr(VI) giderimine düşmektedir. $\mathrm{Cr}(\mathrm{VI})$ giderimi ile $\mathrm{pH}$ arasında ters bir orantı vardır ve $\mathrm{pH}$ düştükçe adsorblanan krom miktarında artış gözlenmiştir. Bu durum, çözelti ortamında fazla $\mathrm{OH}^{-}$iyonunun bulunması ve adsorbanın katyonik bir yapı göstermesi ile açıklanabilir. Ortamda $\mathrm{Cr}(\mathrm{VI})$ türlerinin $\mathrm{HCrO}_{4}{ }^{-}$ve $\mathrm{CrO}_{4}{ }^{2-}$ olduğu bilinmektedir, $\mathrm{pH}$ 4'ün altındaki değerlerde $\mathrm{HCrO}_{4}^{-}$baskın olduğunu söyleyebiliriz [6].

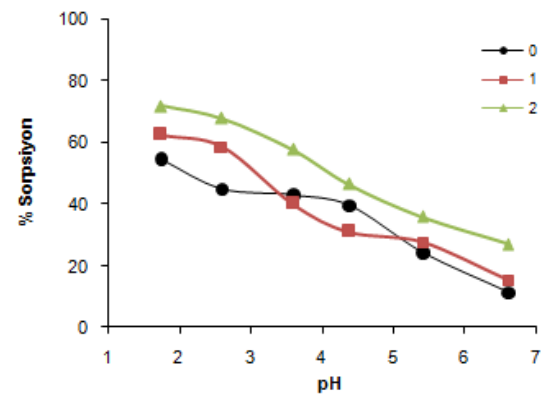

Şekil 7. Mikrokapsüllerin $\mathrm{Cr}(\mathrm{VI})$ giderimi üzerine $\quad \mathrm{pH}$ 'nın etkisi (Cr(VI)

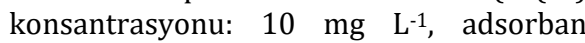
miktarı: $0,1000 \mathrm{~g}$, sıcaklık: $25^{\circ} \mathrm{C}$, karıştırma oranı: 200 rpm, temas süresi: 6 saat)

0-Boş kapsül; 1- Hekzan/metanol çözücüsüyle yıkanan; 2- 2propanol/metanol çözücüsüyle yıkanan

\subsubsection{Konsantrasyon Etkisi}

Farklı başlangıç konsantrasyonlar ile $\mathrm{Cr}(\mathrm{VI})$ gideriminde ulaşılan denge konsantrasyonları belirlenerek birim adsorban başına adsorplanan madde miktarı Freundlich ve Langmuir izotermleri ile açlklanabilecektir. Konsantrasyon etkisini incelemek amacıyla; mikrokapsüller 0,1000'er gram tartılarak; $100 \mathrm{mg} \mathrm{L}^{-1}$ hazırlanan stok Cr(VI) çözeltisinden, 2, 4, 8, 10 ve $12 \mathrm{mg}$ $\mathrm{L}^{-1}$ konsantrasyonlarda $\mathrm{pH}$ : 1,75'e ayarlanmış çözeltiler hazırlanarak, mikrokapsül tartılmış şişelere $25 \mathrm{~mL}$ ilave edilerek ve çalkalamalı inkübatörde 6 saat $25{ }^{\circ} \mathrm{C}$ ' de çalkalanmiştır. Süzüntülerden metal analizleri Contra AA'da ölçülmüştür.

Adsorpsiyon izotermleri bir gram adsorban tarafından adsorplanan $\operatorname{Cr}(\mathrm{VI})$ miktarına karşı çözeltide kalan metal miktarı grafiklendirerek elde edilmiştir. Adsorban fazında tutulan metal iyonu konsantrasyonları aşağıdaki Denklem (1) ile hesaplanmıştır.

$$
q=\left(C_{0}-C\right) V / W
$$

Formülde $\mathrm{C}_{0}(\mathrm{mmol} / \mathrm{L})$ ve $\mathrm{C}(\mathrm{mmol} / \mathrm{L})$ sırasıyla sulu fazdaki baslangıç ve denge 
konsantrasyonlarını göstermektedir. V (L) sulu fazın hacmi, W (g) ise kuru adsorban kütlesidir $[5,6,33]$.

Mikrokapsüllerin bir gram adsorbanın tuttuğu miktarının mmol / g cinsinden değeri Tablo 1'de sırasıyla pH 1,75'de 0 Boș kapsül için 54,3; 1-Hekzan/metanol çözücüsüyle yıkanan için 62.22; 2-2propanol/metanol çözücüsüyle yıkanan için ise $71,57 \mathrm{mg} / \mathrm{g}$ olarak $\mathrm{Cr}(\mathrm{VI})$ giderimi gerçekleştirilmiştir. Yapılan çalışmaya göre sulu çözeltilerden $\mathrm{Cr}(\mathrm{VI})$ iyonları kullanılan mikrokapsüller ile giderilebilir.

Tablo 1. Mikrokapsüllerin Cr(VI) iyon sorpsiyonu için Freundlich ve Langmuir izoterm parametreleri

\begin{tabular}{|c|c|c|c|c|c|c|}
\hline \multirow{4}{*}{ Cr(VI) } & \multicolumn{2}{|c|}{$\begin{array}{c}\text { Freundlich İzoterm } \\
\text { parametresi }\end{array}$} & \multicolumn{2}{|c|}{$\begin{array}{c}\text { Langmuir İzoterm } \\
\text { parametresi }\end{array}$} \\
\cline { 2 - 7 } & \multicolumn{2}{|c|}{$\log q_{e}=\log k+\frac{1}{n} \log C_{e}$} & \multicolumn{2}{|c|}{$\left(C_{e} / q_{e}\right) v s \cdot C_{e}$} \\
\cline { 2 - 6 } & \multicolumn{2}{|c|}{$\log q_{e} v s \cdot \log C_{e}$} & \multicolumn{2}{|c|}{$\left(\boldsymbol{C}_{e} / q_{e}\right) v s \cdot \boldsymbol{C}_{e}$} \\
\hline $\mathbf{0}$ & 25,351 & 0,903 & 0,982 & 14,706 & 151,607 & 0,803 \\
\hline $\mathbf{1}$ & 59,841 & 0,786 & 0,987 & 2,591 & 26,986 & 0,992 \\
\hline $\mathbf{2}$ & 727,780 & 0,550 & 0,970 & 0,589 & 4,826 & 0,968 \\
\hline
\end{tabular}

0-Boş kapsül; 1- Hekzan/metanol çözücüsüyle yıkanan; 2- 2-propanol/metanol çözücüsüyle yıkanan.

Freundlich İzotermleri için, $k$ ve $n$ parametreleri; Langmuir İzotermleri için ise $A_{s}$ ve $K_{b}$ parametreleri hesaplanmıștır $[5,6,33]$. Freundlich izotermindeki $k$ adsorpsiyon kapasitesini gösterirken $n$ sabit bir değerdir. Langmuir izotermindeki $A_{s}$ adsorpsiyon kapasitesi, $K_{b}$ sabiti adsorpsiyon enerjisiyle ilgili bir sabittir. Adsorpsiyon izotermlerinin Langmuir Adsorpsiyon İzotermlerine uygunluk göstermektedir. Düşük Cr(VI) konsantrasyonundaki çözeltilerde metalin kitosanlar tarafindan adsorpsiyonunun hem fiziksel ve hem de kimyasal olarak gerçekleştiği, fiziksel adsorpsiyonun daha etkili olduğu, derișik çözeltilerde ise kimyasal adsorpsiyon ile adsorplandığl, adsorpsiyon bulgularının Langmuir adsorpsiyon izotermine uyduğu söylenebilir. Langmuir izotermi, partikül yüzeyinin homojen olduğunu ve adsorpsiyon potansiyelinin sabit olduğunu kabul eder. Hesaplanan korelasyon katsayılarından Langmuir izoterminin 1-Hekzan/metanol çözücüsüyle yıkanan adsorbanı ile gerçekleştirilmiş $\mathrm{Cr}(\mathrm{VI})$ iyonunun uzaklaștırma ișlemini tanımlamaya daha uygun olduğu görülmektedir. Literatürde verilen $\mathrm{Cr}(\mathrm{VI})$ gideriminde kullanılan farklı adsorbanların adsorpsiyon kapasiteleri Tablo 2'de verilmiştir. Genel olarak, sonuçlar incelendiğinde 2-propanol/metanol çözücüsüyle yıkanan CdSe nanokristallerini içeren kitosan mikrokapsüllerin adsorpsiyon 
A. Soyadı vd. / Çalışmanın ismi her kelimenin ilk harfi büyük (bağlaçlar hariç) ve "Cambria” fontunda 8 punto olacak șekilde buraya eklenmelidir

kapasitesinin yüksek olduğu kapasitesi $71,57 \quad \mathrm{mg} / \mathrm{g} \quad$ olarak görülmüştür. Maksimum adsorpsiyon hesaplanmıştır.

Tablo 2. Farklı adsorbanlar kullanarak Cr(VI) için adsorpsiyon kapasiteleri

\begin{tabular}{|c|c|c|}
\hline Adsorban & $\begin{array}{c}\text { Cr(VI) için } \\
\text { adsorpsiyon } \\
\text { kapasitesi (mg/g) }\end{array}$ & Literatür \\
\hline Linyit & 47,8 & [36] \\
\hline $\begin{array}{l}\text { Hümik asit } \\
\text { (Ilgın, Beyșehir, Ermenek) }\end{array}$ & 28,$6 ; 33,3 ; 20,8$ & {$[37]$} \\
\hline Aktif karbon & 30,2 & [37] \\
\hline Kitosan & 54,5 & [38] \\
\hline Ceviz, Fındık ve Badem kabukları & 8,$01 ; 8,28 ; 3,40$ & [39] \\
\hline $\begin{array}{l}\text { İyon değiştiriciler } \\
\text { (Lewatit MP 64, Lewatit MP 500) }\end{array}$ & 20,$8 ; 21,3$ & [40] \\
\hline $\begin{array}{l}\text { 0-Boş kapsül; 1-Hekzan/metanol } \\
\text { çözücüsüyle yıkanan; 2- 2- } \\
\text { propanol/metanol çözücüsüyle } \\
\text { ylkanan. }\end{array}$ & 54,$30 ; 62,22 ; 71,57$ & $\begin{array}{l}\mathrm{Bu} \\
\text { çalışmada }\end{array}$ \\
\hline
\end{tabular}

\section{Tartışma ve Sonuç}

Hazırlanan mikrokapsülllerin fiziksel yapısı (porozite, yüzey alanı gibi), sorbent miktarı, iyon özellikleri (atomik/iyonik yarıçapları), metal türlerinin başlangıç konsantrasyonları, sterik etkiler, şelat oluşturma hızı ve elbetteki aktif adsorpsiyon bölgeleri için metal iyonlarının ilgisi gibi parametrelerdir. Bu yüzden adsorpsiyon hızlarını diğer yayınlarda bulunanlarla karşılaştırmak çok güçtür [5].

$\mathrm{Bu}$ çalışmada, yüksek sıcaklıkta organometalik başlatıcılar ile ağır metal temelli CdSe nanokristalleri sentezlenmiş ve kitosan katkılı mikrokapsüllerin hazırlanması ile yeni bir nanokompozit mikrokapsül adsorban maddenin sulardan $\mathrm{Cr}$ (VI) gideriminde kullanılmıştır. Sentezlenen CdSe nanokristallerinin geçirimli elektron mikroskobu tekniği (TEM) ve X ışınları saçılım (XRD) ölçümleri ile yapısal analizleri yapılmıştır.
Hazırlanan mikrokapsüllerle $\mathrm{Cr}(\mathrm{VI})$ gideriminde verimli sonuçlar elde edilmiştir. En yüksek giderim pH 1.75' de elde edilmiştir. Optimum adsorban miktarı 0.1000 gram olarak $25 \mathrm{~mL}$ çözelti için belirlenmiş, yeterli adsorpsiyon veriminin sağlanması için gerekli temas süresi ise 6 saat olarak rapor edilmiştir. Aynı zamanda, başlangıç metal konsantrasyonunun artmasıyla $\mathrm{Cr}(\mathrm{VI})$ gideriminin azaldığı da görülmüştür. Elde edilen sonuçlar, Langmuir ve Freundlich adsorpsiyon izotermlerinin her ikisi üzerinde analiz edilmiş, ancak Langmuir adsorpsiyon izotermine daha çok uyduğu tespit edilmiștir.

\section{Kaynakça}

[1] Sarin, V., Pant, K. K., 2006. Removal of Chromium from Industrial Waste by Using Eucalyptus bark, Bioresource Technology, Cilt. 97, s. 15-20. DOI: 10.1016/j.biortech.2005.02.010.

[2] Banerjee S.S., Jayaram R.V., Joshi M.V., 2003. Removal of nickel (II) and zinc (II) from wastewater using 
A. Soyadı vd. / Çalışmanın ismi her kelimenin ilk harfi büyük (bağlaçlar hariç) ve "Cambria” fontunda 8 punto olacak șekilde buraya eklenmelidir

fly ash and impregnated fly ash, Separation Science and Technology, Cilt. 38, s. 1015-1032. DOI: 10.1081/SS-120018121.

[3] Ho, Y., Mckay, G., 1999. PseudoSecond Order Model For Sorption Processes, Process Biochem, Cilt. 34 s. 451-465. DOI: 10.1016/S0032-9592(98)00112-5.

[4] Dakiky, M., Khamıs, M., Manassra, A., Mer'eb, M., 2002. Selective Adsorption of Chromium (VI) In Industrial Wastewater Using LowCost Abundantly Available Adsorbents, Advances In Environ. Res, Cilt. 6, s. 533-540. DOI: 10.1016/S1093-0191(01)00079-X.

[5] Arslan, G., 2004. Bazı Polimerik Sorbentlerin Toksik Metaller ile Sorpsiyon, İyon Değiştirme ve Şelatlaşma Özelliklerinin İncelenmesi, Doktora Tezi, Selçuk Üniversitesi Fen Bilimleri Enstitüsü, Kimya Anabilim Dall, Konya.

[6] Pehlivan, E., Arslan, G., 2007. Batch Removal of Chromium(VI) from Aqueous Solution by Turkish Brown Coals, Bioresource Technology, Cilt. 98, s. 2836-2845. DOI:

10.1016/j.biortech.2006.09.041.

[7] Arslan, G., Pehlivan, E., 2008. Uptake of $\mathrm{Cr}^{+3}$ from Aqueous Solution by Lignite-Based Humic Acids, Bioresource Technology, Cilt. 99, s. 7597-7605. DOI: 10.1016/j.biortech.2008.02.007.

[8] Monllor, P., Bonet, M. A., \& Cases, F., 2007. Characterization of the behaviour of flavour microcapsules in cotton fabrics, European Polymer Journal, Cilt. 43, s. 2481-2490. DOI: 10.1016/j.eurpolymj.2007.04.004.
[9] Patel, R. R., \& Patel, J. K., 2010. Novel technologies of oral controlled release drug delivery system, Systematic Reviews in Pharmacy,Cilt. 1, s. 128-132. DOI: 10.4103/0975-8453.75054.

[10] Estevinho, B.N., Rocha, F., Santos, L., Alves, A., 2013. Microencapsulation with chitosan by spray drying for industry applications, A review, Trends in Food Science \& Technology, Cilt. 31, s. 138-155. DOI: $10.1016 /$ j.tifs.2013.04.001

[11] De Azeredo H.M.C., 2005. Encapsulac, ao: aplicac, ao _a tecnologia de alimentos, Alimentos e Nutric, ao Araraquara, s. 89-97.

[12] Aghbashlo, M., Mobli, H., Rafiee, S., \& Madadlou, 2012. Energy and exergy analyses of the spray drying process of fish oil microencapsulation, Biosystems Engineering, Cilt. 111, s. 229-241. DOI: 10.1080/07373930802412231.

[13] Gharsallaoui A., Roudaut, G., Chambin, O., Voilley, A., \& Saurel, R., 2007. Applications of spray-drying in microencapsulation of food ingredients: an overview, Food Research International, Cilt. 40, s. 1107-1121. DOI: 10.1016/j.foodres.2007.07.004

[14] Gouin S., 2004. Microencapsulation: industrial appraisal of existing technologies and trends, Trends in Food Science \& Technology, Cilt. 15, s. 330-347. DOI: 10.1016/j.tifs.2003.10.005

[15] Muzzarelli R.A.A., Boudrant J., Meyer D., Manno N., DeMarchis M., Paoletti M.G., 2012. Current Views on Fungal Chitin/Chitosan, Human Chitinases, Food Preservation, 
A. Soyadı vd. / Çalışmanın ismi her kelimenin ilk harfi büyük (bağlaçlar hariç) ve "Cambria” fontunda 8 punto olacak şekilde buraya eklenmelidir

Glucans, Pectins and Inulin: A Tribute to Henri Braconnot, Precursor of the Carbohydrate Polymers Science, on the Chitin Bicentennial, Carbohydrate Polymers, Cilt. 87, sp. 995-1012. DOI: 0.1016/j.carbpol.2011.09.063

[16] Hu C.Y., Lo S.L., Chang C.L., Chen F.L., Wu Y.D., Ma J.L., 2013. Treatment of Highly Turbid Water Using Chitosan and Aluminum Salts, Separation and Purification Technology, Cilt. 104, s. 322-326. DOI: 10.1016/j.seppur.2012.11.016

[17] Ahmad A.L., Sumathi S., Hameed B.H., 2005. Residual Oil and Suspended Solid Removal Using Natural Adsorbents Chitosan, Bentonite and Activated Carbon: A Comparative Study, Chemical Engineering Journal, Cilt. 108, s. 179-185. DOI: 10.1016/j.cej.2005.01.016

[18] Ngah W.S.W, Teong L.C., Hanafiah M.A.K.M., 2011. Adsorption of Dyes and Heavy Metal Ions by Chitosan Composites, A Review, Carbohydrate Polymers, Cilt. 83, s. 1446-56. DOI: 10.1016/j.carbpol.2010.11.004

[19] Zemmouria H., Drouiche M., Sayeh A., Lounici H., Mameri N., 2013. Chitosan Application for Treatment of Beni- Amrane's Water Dam, Energy Procedia, Cilt. 36, s. 558-64. DOI: 10.1016/j.egypro.2013.07.064

[20] Zhao, D., He, Z., Chan, W.H., and Choi, M.M.F., 2009. Synthesis and Characterization of High-Quality Water-Soluble Near-InfraredEmitting CdTe/CdS Quantum Dots Capped by $\mathrm{N}$-Acetyl-L-cysteine Via Hydrothermal Method, J. Phys. Chem. C, Cilt. 113, s.1293-1300. DOI: $10.1021 / j p 808465$ s
[21] Wang, R., Calvignanello, O., Ratcliffe, C.I., Wu, X., Leek, D.M., Zaman, Md. B., Kingston, D., Ripmeester, J.A., and Yu, K., 2009. HomogeneouslyAlloyed CdTeSe Single-Sized Nanocrystals with Bandgap Photoluminescence, J. Phys. Chem. C, Cilt. 113, s. 3402-3408. DOI: 10.1021/jp810325z

[22] Alivisatos, A.P., 1996 Semiconductorclusters, nanocrystals, and quantumdots, Science, Cilt. 271, s. 933-937. DOI: 10.1126/science.271.5251.933.

[23] He, R., Gu, H., 2006. Synthesis and characterization of mondispersed CdSe nanocrystals at lower temperature, Colloids and Surfaces A: Physicochem. Eng. Aspects, Cilt. 272, s. 111-116. DOI: 10.1016/j.colsurfa.2005.07.017

[24] Brus, L. E., 1990. Semiconductor crystallites, Acc. Chem. Res., Cilt. 23, ps 183-188. DOI: 10.1021/ar00174a003

[25] Tian, J. , Liu, R. , Zhao, Y. , Xu, Q. , Zhao, S., 2009. Controllable synthesis and cell-imaging studies on CdTe quantum dots together capped by glutathione and thioglycolic acid, Journal of Colloid and Interface Science, Cilt. 336, s. 504-509. DOI: 10.1016/j.jcis.2009.04.064

[26] Deng, Z., Zhang, Y., Yue, J., Tang, F., and We, Q., 2007. Green and Orange CdTe Quantum Dots as Effective pH-Sensitive Fluorescent Probes for Dual Simultaneous and Independent Detection of Viruses, J. Phys. Chem. B, Cilt. 111, s. $12024-$ 12031. DOI: $10.1021 / j p 074609 z$

[27] Han, B., Yuan, J., and Wang, E., 2009. Sensitive and Selective 
A. Soyadı vd. / Çalışmanın ismi her kelimenin ilk harfi büyük (bağlaçlar hariç) ve "Cambria” fontunda 8 punto olacak şekilde buraya eklenmelidir

Sensor for Biothiols in the Cell Based on the Recovered Fluorescence of the CdTe Quantum Dots-Hg(II) System, Anal. Chem., Cilt. 81, s. 5569-5573. DOI: 10.1021/ac900769h

[28] Kumar, S.G. and Rao, K.S.R.K., 2014. Physics and chemistry of CdTe/CdS thin film heterojunction photovoltaic devices: fundamental and critical aspects, Energy Environ. Sci., Cilt. 7, s. 45-102. DOI: 10.1039/C3EE41981A

[29] Cui, R., Pan, H.-C., Zhu, J.-J., and Chen, H.-Y., 2007. Versatile Immunosensor Using CdTe Quantum Dots as Electrochemical and Fluorescent Labels, Anal. Chem., Cilt. 79, s. 8494-8501. DOI: 10.1021/ac070923d

[30] Al-Salim, N., Young, A.G., Tilley, R.D., McQuillan, A.J., and Xia , J., 2007. Synthesis of CdSeS Nanocrystals in Coordinating and Noncoordinating Solvents: Solvent's Role in Evolution of the Optical and Structural Properties, Chem. Mater., Cilt. 19, s. 5185-5193. DOI: $10.1021 / \mathrm{cm} 070818 \mathrm{k}$

[31] Yu, X., Zhao, Z., Nie, W., Deng, R., Liu, S., Liang, R., Zhu, J., and Ji, X., 2011. Biodegradable Polymer Microcapsules Fabrication through a Template-Free Approach, Langmiur, Cilt. 27, s. 10265-10273. DOI: $10.1021 / \mathrm{la2} 201944 \mathrm{~s}$

[32] Tuinenga, C., Jasinski, J., Iwamoto, T., and Chikan, V., 2008. In Situ Observation of Heterogeneous Growth of CdSe Quantum Dots: Effect of Indium Doping on the Growth Kinetics, Acs Nano, Cilt. 2, s. 1411-1421. DOI: $10.1021 / \mathrm{nn} 700377 \mathrm{q}$
[33] Sargın, M., Kaya, G. Arslan, T. Baran, T. Ceter, 2015. Preparation and characterisation of biodegradable pollen-chitosan microcapsules and its application in heavy metal removal, Bioresource Technology, Cilt. 177, s. 1-7. DOI: 10.1016/j.biortech.2014.11.067

[34] Wang, P., Li, D., Chen, J., Zhang, X., Xian, J., Yang, X., Zheng, X., Li, X., Shao, Y., 2014. A novel and green method to synthesize CdSe quantum dots-modified $\mathrm{TiO}_{2}$ and its enhanced visible light photocatalytic activity, Applied Catalysis B: Environmental, Cilt. 160-161, s. 217-226. DOI:doi.org/10.1016/j.apcatb.201 4.05.032

[35] Yu, X.Y., Lei, B. X., Kuang, D. B., Su, C. Y., 2012. High performance and reduced charge recombination of CdSe/CdS quantum dot-sensitized solar cells, J. Mater. Chem., Cilt. 22, s. 12058-12063.

DOI: 10.1039/C2JM16738G

[36] Nakano, Y., Takeshita, K., Tsutsumi, T., 2001. Adsorption mechanism of hexavalent chromium by redox within condensed-tannin gel, Water Research cilt. 5(2), s. 496-500, DOI:10.1016/S00431354(00)00279-7

[37] Arslan, G., Edebali, S., Pehlivan, E., 2010. Physical and chemical factors affecting the adsorption of $\mathrm{Cr}(\mathrm{VI})$ via humic acids extracted from brown coals, Desalination cilt. 255 , s. 117-123, DOI:10.1016/j.desal.2010.01.006

[38] Kocak, N., Sahin, M., Arslan, G., Ucan, H.I., 2012. Synthesis of Crosslinked Chitosan Possessing Schiff Base and Its Use in Metal Removal, Journal of Inorganic and Organometallic Polymers and Materials cilt. 22, s. 
A. Soyadı vd. / Çalışmanın ismi her kelimenin ilk harfi büyük (bağlaçlar hariç) ve "Cambria” fontunda 8 punto olacak şekilde buraya eklenmelidir

166-177, DOI $10.1007 / \mathrm{s} 10904-$

011-9509-3

[39] Pehlivan, E., Altun, T., 2008.

Biosorption of chromium(VI) ion

from aqueous solutions using walnut, hazelnut and almond shell, Journal of Hazardous Materials cilt. 155, S., 378-384, DOI:10.1016/j.jhazmat.2007.11.07 1

[40] Pehlivan, E., Cetin, S., 2009. Sorption of $\mathrm{Cr}(\mathrm{VI})$ ions on two Lewatit-anion exchange resins and their quantitative determination using UV-visible spectrophotometer, Journal of Hazardous Materials cilt. 163, s. 448-453, DOI:10.1016/j.jhazmat.2008.06.1 15 